Research article

Open Access

\title{
Serum 25-hydroxyvitamin D concentrations and postmenopausal breast cancer risk: a nested case control study in the Cancer Prevention Study-II Nutrition Cohort
}

\author{
Marjorie L McCullough1, Victoria L Stevens ${ }^{1}$, Roshni Patel1, Eric J Jacobs ${ }^{1}$, Elizabeth B Bain ${ }^{1}$, \\ Ronald L Horst ${ }^{2}$, Susan M Gapstur ${ }^{1}$, Michael J Thun ${ }^{1}$ and Eugenia E Calle ${ }^{1 \wedge}$
}

\author{
${ }^{1}$ Epidemiology Research, American Cancer Society, 240 Williams Street, Atlanta, GA 30303-1002, USA \\ ${ }^{2}$ Heartlands Assays, Inc. 2325 N. Loop Drive, Suite 6300, Ames, IA 50010, USA \\ Corresponding author: Marjorie L McCullough, marji.mccullough@cancer.org \\ ${ }^{\wedge}$ Deceased
}

Received: 3 Jun 2009 Revisions requested: 7 Jul 2009 Revisions received: 13 Aug 2009 Accepted: 28 Aug 2009 Published: 28 Aug 2009

Breast Cancer Research 2009, 11:R64 (doi:10.1186/bcr2356)

This article is online at: http://breast-cancer-research.com/content/11/4/R64

(c) 2009 McCullough et al.; licensee BioMed Central Ltd.

This is an open access article distributed under the terms of the Creative Commons Attribution License (http://creativecommons.org/licenses/by/2.0), which permits unrestricted use, distribution, and reproduction in any medium, provided the original work is properly cited.

\begin{abstract}
Introduction Vitamin D status measured during adulthood has been inversely associated with breast cancer risk in some, but not all, studies. Vitamin $\mathrm{D}$ has been hypothesized to prevent breast cancer through genomic and non-genomic actions in cell-cycle regulation.

Methods A subset $(n=21,965)$ of female participants from the prospective Cancer Prevention Study-II (CPS-II) Nutrition Cohort provided a blood sample from 1998-2001 and were followed through 2005. We measured serum 25-hydroxyvitamin $\mathrm{D}(25(\mathrm{OH}) \mathrm{D})$ in 516 verified incident cases and 516 controls, matched on birth date ( \pm 6 months), date of blood draw ( \pm 6 months) and race. Information on medical history, risk factors and lifestyle was available from repeated questionnaires. We computed multi-variable odds ratios (OR) and 95\% confidence intervals $(95 \% \mathrm{Cl})$ for the association between $25(\mathrm{OH}) \mathrm{D}$ quintile and breast cancer risk using unconditional logistic
\end{abstract}

regression, controlling for matching factors and additional confounders.

Results We observed no association between 25(OH)D and breast cancer $(\mathrm{OR}=1.09,95 \% \mathrm{Cl} 0.70-1.68, P=0.60)$ for the top vs bottom quintile. Using a priori cut-points, the OR was 0.86 (95\% Cl 0.59-1.26), for $\geq 75$ vs $<50 \mathrm{nmol} / \mathrm{L}$. Results were not different when the first two years of follow-up were excluded, or in analyses stratified by season, latitude, BMl, postmenopausal hormone use, or by tumor grade or estrogen receptor status.

Conclusions These results do not support an association between adulthood serum 25(OH)D and postmenopausal breast cancer. We cannot rule out an association with $25(\mathrm{OH}) \mathrm{D}$ status earlier in life.

\section{Introduction}

Although breast cancer death rates have declined in recent years, breast cancer remains the most commonly diagnosed cancer and the second leading cause of cancer death in women in the US. [1]. Risk factors include family history, high breast tissue density, long menstrual history (menstrual periods that begin early and end late in life), nulliparity, late age at first birth, use of hormone replacement therapy, regular alcohol consumption, low physical activity, high body mass index
(BMI) and weight gain during adulthood (for postmenopausal breast cancer). Apart from energy imbalance, dietary risk factors have not been consistently associated with risk of the disease [2].

Breast cancer rates are higher in areas of the US with lower overall ultraviolet $B$ radiation exposure, raising the possibility that higher levels of vitamin D could reduce breast cancer risk [3]. Vitamin D may regulate cell proliferation and differentiation 
through both genomic and non-genomic effects [4]. Epidemiologic studies have observed lower breast cancer risk with greater self-reported [5] and measured [6] sun exposure. The association between dietary and supplemental intake of vitamin $\mathrm{D}$ with breast cancer risk has been inconsistent [7], potentially because typical doses of vitamin $D$ intake have comparatively less impact on vitamin $D$ status than ultraviolet $B$ exposure, and because of measurement error in nutrition assessment. Circulating 25-hydroxyvitamin D $(25(\mathrm{OH}) \mathrm{D})$ reflects an input of vitamin $\mathrm{D}$ from both sun exposure and diet over the preceding several weeks, and thus represents an integrated measure of vitamin $D$ status. This metabolite is thought to be relevant because it provides substrate for tissue-specific synthesis of the active form of vitamin $D(1,25$-dihydroxyvita$\left.\min \mathrm{D}\left(1,25(\mathrm{OH})_{2} \mathrm{D}\right)\right)$, the natural ligand for the nuclear vitamin $\mathrm{D}$ receptor. Although three case-control studies reported an inverse relation between circulating $25(\mathrm{OH}) \mathrm{D}$ and breast cancer risk [8-10], results from three nested case-control studies where blood was collected prior to diagnosis were less consistent [11-13].

If vitamin D status is associated with a lower risk of breast cancer, this would represent an easily modifiable risk factor. To contribute to the limited and inconsistent prospective data on this topic of important public health interest, we examined circulating $25(\mathrm{OH}) \mathrm{D}$ concentrations in a nested case-control study of over 500 postmenopausal breast cancer cases and their matched controls from the Cancer Prevention Study-II (CPS-II).

\section{Materials and methods Study population}

Women in this analysis were participants in the CPS-II Nutrition Cohort, a prospective study of cancer incidence among men and women from 21 states in the US, established by the American Cancer Society in 1992 [14]. At enrollment, 86,404 men and 97,788 women completed a 10-page, self-administered questionnaire on medical, dietary, reproductive, and lifestyle variables. Beginning in 1997, follow-up questionnaires were sent to cohort members every two years to update exposure information and to ascertain newly diagnosed cancers. All aspects of the CPS-II cohort were approved by the Emory University (Atlanta, GA, USA) Institutional Review Board.

\section{Breast cancer nested case-control study}

From June 1998 to June 2001, blood specimens were collected from 21,965 women in the Nutrition Cohort who lived near a major collaborating hospital or medical clinic in their community, as described in detail elsewhere [14]. All participants completed a brief questionnaire and provided informed consent at the time of blood draw. We collected a maximum of $43 \mathrm{~mL}$ of nonfasting whole blood from each participant drawn in two $15 \mathrm{~mL}$ tubes containing the anticoagulant ethylenediamine tetraacetic acid and a $13 \mathrm{~mL}$ serum separator tube. Hospital staff centrifuged the serum separator tubes to separate serum from cellular blood components prior to shipping, and all samples were then shipped in foam containers with coolant packs overnight by Express Mail to a central repository in Rockville, Maryland. Shipments of blood from the field were received, unpacked, aliquoted, and frozen in liquid nitrogen vapor phase at approximately $-130^{\circ} \mathrm{C}$ for long-term storage [14].

Eligible cases included women who reported a new diagnosis of breast cancer on a biennial CPS-II Nutrition Cohort Survey between the date of their blood draw and 30 June, 2005 ( $n=$ 514) or who did not report an incident breast cancer but for whom fatal breast cancer was identified through linkage with the National Death Index [16] $(n=2)$. We asked women reporting a diagnosis for permission to review their medical records to confirm their diagnosis. If medical records were not available, we contacted state cancer registries. Previous pilot work in this cohort found that the sensitivity of self-reported breast cancer was 91\% [15] suggesting we successfully ascertained incident breast cancer cases in the cohort.

We initially identified a total of 535 breast cancers diagnosed after the date of blood draw. We excluded women who were pre- or peri-menopausal $(n=3)$ at baseline, those with no appropriate match $(n=1)$, women with one or less vial of serum $(n=14)$, and one woman with an extreme 25(OH)D level (more than three standard deviations above the mean). The analysis is based on 516 cases and on an equal number of matched controls, aged 47 to 85 years at baseline. The duration of follow-up between the date of blood draw and breast cancer diagnosis ranged from less than 1 month to 6.9 years.

We documented the estrogen receptor (ER) and progesterone receptor (PR) status of the tumors from medical record reports and through state cancer registries, when available. Information on ER and PR status was available for $76 \%$ and $73 \%$ of cases, respectively.

\section{Control selection}

Each control was individually matched to a case on birth date ( \pm 6 months), race/ethnicity (Caucasian, African-American, other/unknown), and date of blood collection ( \pm 6 months). We randomly selected one postmenopausal female control who had provided a blood sample and was cancer free (except for non-melanoma skin cancer) at the date of the diagnosis of the case. For two cases of 'other' race, an appropriately matched control was not available, and they were matched to a Caucasian control.

\section{Vitamin D assays}

Laboratory analyses were conducted at Heartland Assays, Inc (Ames, IA, USA). Case-control pairs were analyzed in the same batch in no particular order. A direct, competitive chemiluminescence immunoassay using the DiaSorin LIAISON plat- 
form, as described in detail elsewhere [17], was used to quantitate $25(\mathrm{OH}) \mathrm{D}$ levels.

\section{Quality control}

An average of five quality control samples were included in each batch of 100 samples. These quality control samples were from four separate sources: a pooled sample of non-multivitamin users, a pooled sample of multivitamin users, and two individual CPS-II Nutrition Cohort participants.

Coefficients of variation (CV) for duplicate serum aliquots included in all laboratory sample batches were calculated for each of the four quality control samples, and ranged from 6.4 to $8.8 \%$. Intra-batch and inter-batch CVs were $5.4 \%$ and $8.1 \%$, respectively.

\section{Measurement of covariates}

Information on breast cancer risk factors and potential confounders was ascertained from responses to biennial questionnaires from the CPS-II cohort. For the current analysis, we obtained information on current BMI, date of blood draw, and use of individual vitamin $D$ supplements from the brief questionnaire completed at blood draw. Information on reproductive risk factors, history of benign breast disease, family history and education was assessed on earlier questionnaires. Other variables, including alcohol use, postmenopausal hormone use, diet, recreational physical activity and zip code (for latitude) were collected from the comprehensive 1999 questionnaire. For these variables, 24 cases $(5 \%)$ completed the questionnaire after diagnosis of breast cancer. Sensitivity analyses removing these cases and their controls did not change the risk estimates.

\section{Data analysis}

Circulating 25(OH)D (nmol/L) was normally distributed and was not improved with log transformation; thus, we used untransformed values. We divided participants into quintiles based on the distribution of serum $25(\mathrm{OH}) \mathrm{D}$ in the control group. We observed the expected differences in $25(\mathrm{OH}) \mathrm{D}$ concentrations by season of blood draw: mean levels $( \pm$ standard deviation) were 49.1 ( \pm 21.2 ) in Winter (December to February), 53.7 ( \pm 25.1) in Spring (March to May), 58.1 ( \pm 22.2) in Summer (June to August) and 59.5 ( \pm 20.3) in Fall (September to November). For stratified analyses, we classified season according to two general seasons: a 'warm' season (June to November) and a 'cool' season (December to May). Independent correlates of $25(\mathrm{OH}) \mathrm{D}$ among controls in our study were evaluated using linear regression models.

Our primary statistical approach used unconditional logistic regression to estimate the odds ratio (OR) and 95\% confidence intervals $(\mathrm{Cl})$ for risk of cancer comparing quintiles 2 to 5 with the lowest quintile, to preserve statistical power when conducting stratified analyses on factors that were not matched by design. In sensitivity analyses, we also conducted conditional logistic regression on main effects models and results were similar. We first assessed the relation between serum 25(OH)D and breast cancer risk adjusting only for matching factors (date of birth \pm six months, date of serum collection \pm six months, race (white, other)).

In addition to controlling for matching factors, we included as covariates those factors that were correlated with serum $25(\mathrm{OH}) \mathrm{D}$ concentrations and/or related to breast cancer risk in this sample. These included: season of serum collection (Winter/Spring/Summer/Fall); weight change since age 18 years (lost $>5 \mathrm{~kg}$, lost or gained $<5 \mathrm{~kg}$, gained 5 to $<10,10$ to $<20,20$ to $<30$, and $30+\mathrm{kg}$, and missing data); body mass index $(<22.5,22.5$ to $<25.0,25.0$ to $<30$ (and missing data), $30.0+$ ), and combinations of number of live births (nulliparous, 1 to $2,3+)$ and age of mother at first birth $(<25$ or $\geq 25)$. Adjustment for alcohol consumption (non-drinker, $<1$ drink/ day, $1+$ drink/day, missing data); recreational physical activity in metabolic equivalents (MET) hours per week (quartiles); family history of breast cancer (yes, no); history of benign breast disease (yes, no); age at menarche $(<12,12,13$ (and missing data), $>13$ years); age at menopause $(<45,45-<50$, $50-<54,54+$ years), and postmenopausal hormone use (never, former, current) did not change the effect estimates and therefore were not included. To test for trend, we created a continuous variable consisting of the median $25(\mathrm{OH}) \mathrm{D}$ value from each quintile, and included this variable in the regression model.

We additionally examined the association between $25(\mathrm{OH}) \mathrm{D}$ and breast cancer risk using a priori cut-points of less than 50 $\mathrm{nmol} / \mathrm{L}$ as deficiency (referent), 50 to less than $75 \mathrm{nmol} / \mathrm{L}$ as 'insufficient', and 75+ nmol/L as 'adequate' [18]. We examined the possibility of a non-linear relation between circulating 25(OH)D and breast cancer risk using restricted cubic splines [19]. The linearity of the association between $25(\mathrm{OH}) \mathrm{D}$ and breast cancer risk was tested using the likelihood ratio test, comparing the model with only the linear term to the model with the linear and the cubic spline terms.

We conducted stratified analyses comparing breast cancer risk across tertiles of $25(\mathrm{OH}) \mathrm{D}$ concentration within strata of postmenopausal hormone use (never and ever use), BMI $(<25$ and $\geq 25 \mathrm{~kg} / \mathrm{m}^{2}$ ), time of year of blood draw ('warm' and 'cool' seasons), latitude (above and $\leq 37^{\circ}$ ), tertile of total calcium intake, multivitamin supplement use (assessed in 1999) and use of individual vitamin D supplements (yes, no) reported at blood draw. Interaction terms were cross-product terms of the tertile measure $(0,1,2$, in continuous form) and dummy variables for potential effect modifiers. Multiplicative interactions were evaluated using the likelihood ratio test.

We conducted sensitivity analyses excluding cases diagnosed during the first two years of follow-up, and using season-specific 25(OH)D quintile cut-points [20]. We also 
evaluated the association between $25(\mathrm{OH}) \mathrm{D}$ and breast cancer according to ER status of the tumor, and according to tumor invasiveness (in situ, local, regional/distant). All statistical analyses were conducted using SASv.9.2 (SAS Institute, Inc., Cary, NC, USA).

\section{Results}

Characteristics of the postmenopausal breast cancer cases and controls are provided in Table 1 . The age and race of participants were similar, as expected based on matching criteria. Although the mean BMI was not different between cases and controls, breast cancer cases had gained more weight since age 18 compared with controls. A greater percentage of cases reported a family history of breast cancer, a personal history of benign breast disease, and a later age at menopause. Controls had more children earlier in life compared with cases. There was no difference in the percentage of cases and controls currently or formerly taking postmenopausal hormones. A slightly higher (non-significant) percentage of cases consumed more than one alcoholic drink per day. Recreational physical activity and use of nutritional supplements were not appreciably different between cases and controls.

Several factors predicted circulating 25(OH)D among controls (results not shown). Winter season predicted significantly lower 25(OH)D concentrations compared with Summer. Current $\mathrm{BMI}$ and weight gain each individually predicted $25(\mathrm{OH}) \mathrm{D}$, but when considered simultaneously, current BMI was the stronger predictor. Recreational physical activity was associated with significantly higher concentrations, likely due to greater sunlight exposure during outdoor exercise. Total vitamin D intake (which was not considered as a confounder due to potential over-control) was a statistically significant predictor of $25(\mathrm{OH}) \mathrm{D}$ in univariate and multivariate models. An increment of $800 \mathrm{IU}$ vitamin D corresponded to a $16 \mathrm{nmol} / \mathrm{L}$ higher circulating $25(\mathrm{OH}) \mathrm{D}$ in both models (not shown).

Table 2 presents the OR and $95 \% \mathrm{Cl}$ for the association between quintile of $25(\mathrm{OH}) \mathrm{D}$ and postmenopausal breast cancer risk. Compared with women in the lowest 25(OH)D quintile $(<36.7 \mathrm{nmol} / \mathrm{L})$, the OR for women in the highest quintile $(>73.2 \mathrm{nmol} / \mathrm{L})$ was $1.09(0.70$ to $1.68 ; P=0.6)$. A cubic spline graph (Figure 1) illustrates this association with knots forced at quintile cut-points. An apparent inverse U-shaped association was not statistically significantly non-linear $(P=$ 0.54). Results were similar when 227 cases diagnosed in the first two years after blood draw were excluded (OR for fifth vs first quintile $=1.04,95 \% \mathrm{Cl} 0.62$ to 1.75 , not shown). Results using season-specific $25(\mathrm{OH}) \mathrm{D}$ cut-points were also similar (OR for fifth vs first quintile $=1.13,95^{\text {th }} \mathrm{Cl} 0.74-1.72$ ). In subanalyses using absolute cut-points of 75 or more vs less than $50 \mathrm{nmol} / \mathrm{L}$, the ORs remained null for all cases $(0.86,95 \% \mathrm{Cl}$ 0.59 to $1.26 ; P=0.7$ ).
Associations by ER status and tumor subtype were examined using tertiles of $25(\mathrm{OH}) \mathrm{D}$ concentration to allow comparison among groups with smaller numbers (Table 2). There were no differences by ER status of the tumor, and addition of PR status combined with ER status did not meaningfully affect the results. Likewise, there were no differences in results when tumors were classified as in situ, localized, or regional/distant. In sub-analyses using absolute cut-points of 75 or more vs less than $50 \mathrm{nmol} / \mathrm{L}$; ORs $( \pm 95 \mathrm{Cl}$ ) were: $\mathrm{ER}+, \mathrm{OR}=0.86$, $95 \% \mathrm{Cl} 0.56$ to $1.32, P=0.8$; ER-, OR $=0.90,95 \% \mathrm{Cl} 0.35$ to $2.30, P=1.0$; in situ, $\mathrm{OR}=0.64,95 \% \mathrm{Cl} 0.32$ to $1.30, P$ $=0.3$; localized, $\mathrm{OR}=1.16,95 \% \mathrm{Cl} 0.76$ to $1.78, P=0.3$; regional and distant, $\mathrm{OR}=0.39,95 \% \mathrm{Cl} 0.16$ to $0.92, P=$ 0.08 . Thus, when using established cut-points, individuals who had sufficient vs. deficient levels were at borderline lower risk for regional/distant tumors. When modeled by each 10 $\mathrm{nmol} / \mathrm{L}$ change in $25(\mathrm{OH}) \mathrm{D}$, the multivariate-adjusted ORs and $95 \%$ Cls were as follows: all cases (1.01, 0.95 to 1.07); ER+ cases (1.02, 0.96 to 1.09); ER- cases (0.91, 0.78 to $1.06)$; in situ cases $(0.99,0.90$ to 1.09$)$; localized cases $(1.04,0.97$ to 1.10$)$ and regional/distant cases $(0.93,0.83$ to 1.05).

The association between 25(OH)D and breast cancer risk did not vary by history of postmenopausal hormonal therapy, BMI, weight gain, 'warm' and 'cool' season of blood draw, or calcium intake. A significant interaction was observed by latitude: the OR among women living at $37^{\circ}$ or more latitude who were in the top tertile of $25(\mathrm{OH}) \mathrm{D}(64 \mathrm{nmol} / \mathrm{L}+)$ vs bottom tertile ( $<46 \mathrm{nmol} / \mathrm{L}$ ) was 0.35 (95\% Cl 0.17 to 0.73 ), vs $\mathrm{OR}=1.07$ $(95 \% \mathrm{Cl} 0.59$ to 1.95$)$ among women living at $<37^{\circ}(P$ interaction $=0.003$ ). The relation did not vary by use of vitamin $D$ containing multivitamin supplements (measured in 1999), but a significant interaction was observed for use of individual vitamin D supplements (yes, no) at blood draw: among women who reported not using vitamin D supplements, the OR for the top vs bottom tertile was 0.82 ( $95 \% \mathrm{Cl} 0.53$ to 1.27$)$, whereas among current users it was 1.82 ( 0.61 to $5.39 ; P$ interaction $=0.047$ ).

\section{Discussion}

In this nested case-control study of mostly Caucasian women, serum $25(\mathrm{OH}) \mathrm{D}$ concentrations assessed up to six years prior to diagnosis were not associated with risk of postmenopausal breast cancer. This finding did not change when we excluded cases occurring in the first two years after blood draw, and were not significantly different in analyses stratified by BMI, postmenopausal hormone use, season of blood draw, calcium intake, or multivitamin use. Likewise, $25(\mathrm{OH}) \mathrm{D}$ concentrations were not significantly associated with cancer subgroups defined on the basis of ER/PR status, or tumor stage/grade.

Our findings contribute to the relatively few prospective studies published on this topic [11-13]. In a nested case-control analysis of 701 cases and 724 controls from the Nurses' 
Table 1

\begin{tabular}{|c|c|c|c|}
\hline Characteristic & Cases $(n=516)$ & Controls $(n=516)$ & $P$ value $\neq$ \\
\hline & \multicolumn{3}{|c|}{ Mean (SD) } \\
\hline Age at serum collection (year) & $69.5(5.9)$ & $69.6(5.8)$ & 0.7 \\
\hline Plasma 25(OH)D (nmol/L) & $56.5(22.0)$ & $56.2(22.2)$ & 0.8 \\
\hline Latitude (degree) & $39.0(4.7)$ & $39.3(4.8)$ & 0.2 \\
\hline $\mathrm{BMI}$ at blood collection $\left(\mathrm{kg} / \mathrm{m}^{2}\right)$ & $25.9(4.9)$ & $25.8(4.8)$ & 0.9 \\
\hline Weight gain since age $18(\mathrm{~kg})$ & $14.1(15.5)$ & $11.1(18.3)$ & 0.006 \\
\hline Exercise METS ${ }^{\dagger}$ & $15.4(13.8)$ & $15.6(14.7)$ & 0.9 \\
\hline Age at menarche (years) & $12.7(1.5)$ & $12.7(1.4)$ & 0.6 \\
\hline \multirow[t]{2}{*}{ Age at menopause (years) } & $48.6(6.1)$ & $47.8(6.0)$ & 0.03 \\
\hline & \multicolumn{3}{|c|}{ Percentage (\%) } \\
\hline Family history of breast cancer & 23.6 & 16.9 & 0.007 \\
\hline History of benign breast disease & 33.9 & 27.5 & 0.01 \\
\hline \multicolumn{4}{|l|}{ Race } \\
\hline White & 96.7 & 97.1 & 0.7 \\
\hline Other (Black/Hispanic/Oriental) & 3.3 & 2.9 & \\
\hline College graduate & 24.2 & 23.4 & 0.5 \\
\hline \multicolumn{4}{|l|}{ Parity and age at first birth } \\
\hline Nulliparous & 9.1 & 8.5 & 0.006 \\
\hline$<25,1$ to 2 live births & 13.2 & 12.4 & \\
\hline $25+, 1$ to 2 live births & 22.5 & 14.7 & \\
\hline$<25,3+$ live births & 35.3 & 45.0 & \\
\hline $25+, 3+$ live births & 20.0 & 19.4 & \\
\hline \multicolumn{4}{|l|}{ Postmenopausal hormone use } \\
\hline Never & 22.1 & 25.4 & 0.4 \\
\hline Former & 58.1 & 53.1 & \\
\hline Current & 16.1 & 16.7 & \\
\hline \multicolumn{4}{|l|}{ Season of blood collection } \\
\hline Dec to Feb & 15.1 & 18.2 & 0.1 \\
\hline Mar to May & 18.8 & 17.4 & \\
\hline Jun to Aug & 35.1 & 29.5 & \\
\hline Sep to Nov & 31.0 & 34.9 & \\
\hline Alcohol intake ( $\geq 1$ drink/day) & 21.3 & 16.1 & 0.1 \\
\hline \multicolumn{4}{|l|}{ Multivitamin use containing vitamin $\mathrm{D}^{\ddagger}$} \\
\hline Not current user & 30.8 & 34.9 & 0.6 \\
\hline Current user & 63.6 & 59.6 & \\
\hline \multicolumn{4}{|l|}{ Calcium supplement use } \\
\hline Not current user & 32.4 & 32.9 & 0.5 \\
\hline Current user & 59.9 & 57.3 & \\
\hline
\end{tabular}


Table 1 (Continued)

Baseline characteristics in cases and controls, CPS II Nutrition Cohort Women (1999 to 2005)*

Vitamin D supplement use $§$

Not current user 54.1

$\begin{array}{ll}53.1 & 53.7\end{array}$

0.9

Current user

16.1

16.9

Mean (SD)

Dietary variables $\#$

Total calcium (mg/day)

$1358.0(565.2)$

Dietary calcium (mg/day)

$777.0(285.3)$

Supplemental calcium (mg/day)

$581.0(504.3)$

Total vitamin D (IU/day)

439.5 (243.6)

Dietary vitamin D (IU/day)

192.0 (105.3)

$\begin{array}{cc}1293.7(576.6) & 0.08 \\ 768.6(283.0) & 0.6 \\ 515.09493 .4) & 0.08 \\ 415.0(239.7) & 0.1 \\ 187.6(96.1) & 0.5\end{array}$

* Standardized to age distribution of the study population.

† Metabolic equivalent of task (METS) are defined for each type of exercise-related physical activity as a multiple of metabolic equivalent of sitting quietly for one hour.

$\neq$ Reported on the 1999 questionnaire.

$\S$ Reported at blood collection.

\# All dietary variables are adjusted for energy intake which was estimated from the 1992 brief Block Food Frequency Questionnaire (FFQ). \#+t+ $P$ values for categorical variables are based on the chi-squared test and $P$ values for continuous variables are based on the $t$-test for difference of means.

25(OH)D = 25-hydroxyvitamin D; BMI = body mass index; CPS-II = Cancer Prevention Study-II; SD = standard deviation.

Health Study, Bertone and colleagues [11] observed a borderline $27 \%$ lower relative risk of breast cancer comparing women in the top vs bottom $25(\mathrm{OH}) \mathrm{D}$ quintile $(P=0.06)$. In contrast, among 1005 postmenopausal cases and 1005 controls from the Prostate, Lung, Colorectal and Ovarian Cancer Screening Trial [13], no association between prediagnostic $25(\mathrm{OH}) \mathrm{D}$ and breast cancer risk was found $(\mathrm{OR}=1.04$, $95 \% \mathrm{Cl} 0.75$ to 1.45$)$, comparing top ( $\geq 84 \mathrm{nmol} / \mathrm{L}$ ) to bottom $(<45.8 \mathrm{nmol} / \mathrm{L})$ quintile. A prospective analysis from the NHANES study [12] reported a relative risk for fatal breast cancer ( $\mathrm{n}=28$ cases) among women with $62.5 \mathrm{nmol} / \mathrm{L}$ or higher vs less than $62.5 \mathrm{nmol} / \mathrm{L}$ circulating $25(\mathrm{OH}) \mathrm{D}$ of 0.28 (95\% $\mathrm{Cl} 0.08$ to $0.93 ; P$ trend of continuous $25(\mathrm{OH}) \mathrm{D}=0.76$ ) [12]. All three published case-control studies [8-10] reported statistically significant inverse associations between circulating 25(OH)D and breast cancer risk. However, because blood was drawn after cancer diagnosis, it is possible that cancer diagnosis may have influenced circulating $25(\mathrm{OH}) \mathrm{D}$ through treatment or behavioral changes. Finally, reports from two randomized controlled trials of vitamin $D$ and/or calcium supplementation were indeterminate [21,22]. A seven-year randomized trial observed no difference in breast cancer risk for women receiving $400 \mathrm{IU}$ vs placebo [21], but the intervention study dose was relatively low and a high percentage of women in the control group began taking supplements during the trial. The other study found a lower risk of overall cancer with the use of $1100 \mathrm{IU}$ vitamin $\mathrm{D}$ in a secondary analysis from an osteoporosis trial [22], but there were too few breast cancers to examine this outcome separately.
Our study did not indicate the existence of a threshold for a protective association with breast cancer with circulating $25(\mathrm{OH}) \mathrm{D}$, which has been hypothesized by some [23]. In the Nurses' Health Study, risk was lower starting at an approximate threshold of 70 to $80 \mathrm{nmol} / \mathrm{L}$ (different cut-points were employed by batch) [11]. Similar to our findings, Freedman and colleagues [13] found no association overall, with a nonsignificant slightly higher breast cancer risk in the middle quantiles of circulating 25(OH)D. Because the shape of the $25(\mathrm{OH}) \mathrm{D}$ - breast cancer association in the current study indicated a lower risk at both ends of the distribution, ORs were sensitive to the cut-points used. For example, in analyses using quintiles, $25(\mathrm{OH}) \mathrm{D}$ concentrations in the middle quantiles were associated with slightly higher risk. However, when we used a priori cut-points for deficiency, insufficiency and sufficiency [18], which resulted in shifting the referent group to higher $25(\mathrm{OH}) \mathrm{D}$ concentrations, there was no suggestion of increased risk in any category.

Body fat and weight gain were moderate negative confounders in our study (with the net effect of raising the OR when added to either the age-adjusted model or multivariate models), and BMI independently predicted circulating 25(OH)D. Body fat is a large storage reservoir for $25-\mathrm{OH}$-vitamin $\mathrm{D}$, and lower circulating $25(\mathrm{OH}) \mathrm{D}$ in obese individuals is thought to be related to greater uptake into fat tissues, rather than lower sun exposure or less effective vitamin $D$ synthesis [24]. In the Women's Health Initiative [21], baseline 25(OH)D was associated with a significantly lower risk of breast cancer, until models were further adjusted for BMI and physical activity. 
Figure 1

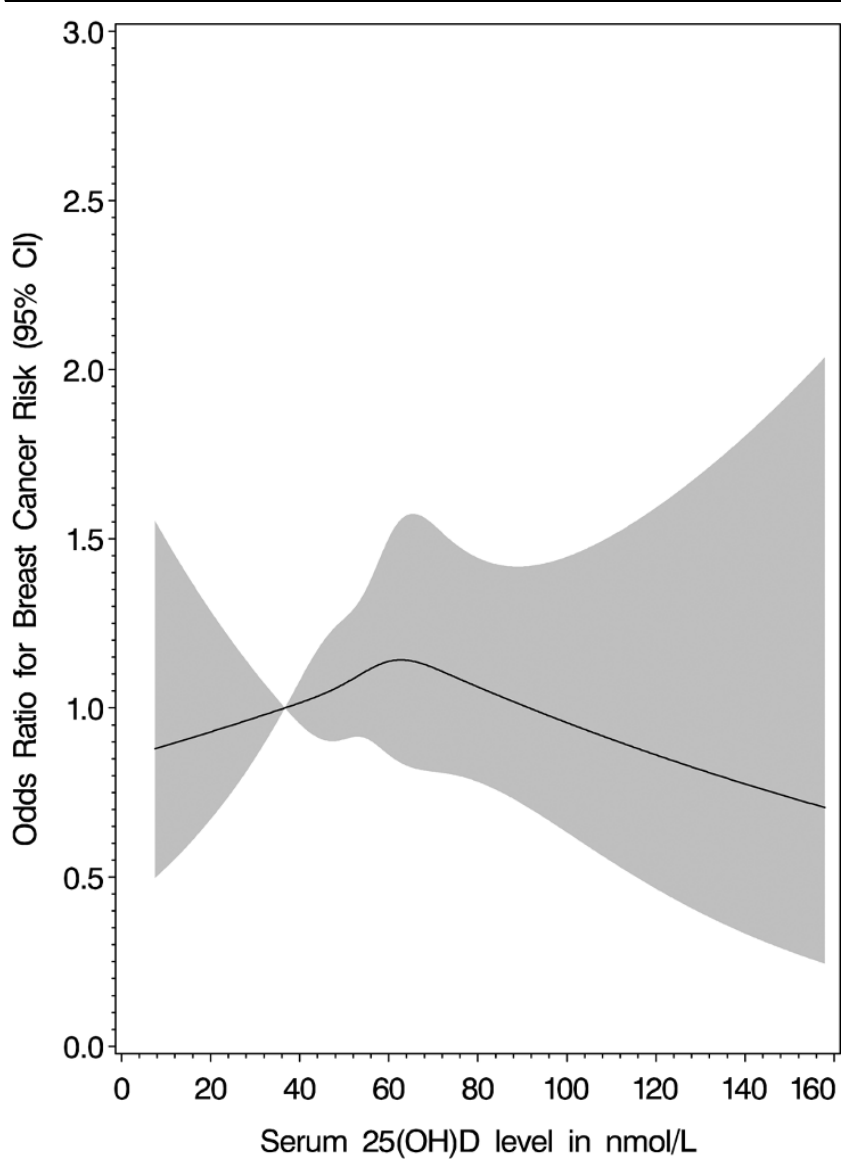

Restricted cubic spline showing the fully adjusted associations between serum 25(OH)D levels and breast cancer risk in 1032 participants in the Cancer Prevention Study-II Nutrition Cohort. The reference value is less than $36.7 \mathrm{nmol} / \mathrm{L}$. The knots are defined by the quintile cut points for 25-hydroxyvitamin $\mathrm{D}(25(\mathrm{OH}) \mathrm{D})$ and are $36.7,49.8,60.8$, and 73.2.

Studies of vitamin D and cancer risk need to carefully examine and control for potential confounding by obesity.

We found that $25(\mathrm{OH}) \mathrm{D}$-breast cancer associations were modified by individual vitamin $D$ supplement use at blood draw, with an inverse association among non-current vitamin $D$ supplement users and a positive association among current supplement users $(P$ interaction $=0.047)$. Reasons for this apparent interaction are unclear. It is possible that the source of vitamin $\mathrm{D}$ may be important. For example, at any given level of serum $25(\mathrm{OH}) \mathrm{D}$, non-supplement users obtain a higher proportion of their vitamin D from cutaneous synthesis, and/or greater intake of fortified milk or fish than do supplement users. Vitamin $\mathrm{D}$ in the diet is strongly correlated with dietary calcium, which also may play a role in preventing breast carcinogenesis $[25,26]$. We also observed a significant inverse association between $25(\mathrm{OH}) \mathrm{D}$ and breast cancer risk among women living in northern $\left(>37^{\circ}\right)$, but not southern $\left(\leq 37^{\circ}\right)$ latitudes. Over $95 \%$ of women in this analysis living in the north were born in the north, whereas $64 \%$ of the women living at $37^{\circ}$ or lower latitude were born in the south. It is possible that low $25(\mathrm{OH}) \mathrm{D}$ concentrations among women living in the north correlate better with chronically low concentrations. However, both of these interactions may also be due to chance.

A potential explanation for our null findings is that we missed the etiologically relevant time frame of vitamin $D$ exposure for breast carcinogenesis. Several studies observed stronger inverse associations between greater intake of vitamin $D$ and/ or calcium in relation to mammographic density or breast cancer among premenopausal women $[9,25,27-29]$ than postmenopausal women. In addition, self-reported sun exposure earlier in life was more strongly associated with postmenopausal breast cancer than sun exposure later in life [30]. We were unable to examine the relation between $25(\mathrm{OH}) \mathrm{D}$ and premenopausal breast cancer, or earlier life vitamin $D$ exposure in relation to postmenopausal breast cancer. Additional limitations include a lower range of circulating $25(\mathrm{OH}) \mathrm{D}$ compared with some other studies $[8,11,13]$, limiting our ability to examine higher cut-points of $25(\mathrm{OH}) \mathrm{D}$ status. This study also had a relatively small sample size, particularly when examining associations by tumor receptor status and subtype.

An advantage of this study is the use of an objective biomarker of vitamin D status, which reflects the integration of dietary and supplemental vitamin $D$ intake as well as cutaneous synthesis. It is possible, however, that our single measure of $25(\mathrm{OH}) \mathrm{D}$ did not correctly classify women according to their usual, yearround vitamin D status. Circulating 25(OH)D reflects exposure to sun and diet from approximately the prior two months. Further, 25(OH)D fluctuates according to season of the year. To minimize this extraneous source of variation, we controlled for season of blood draw, and in sensitivity analyses, we used season-specific cut-points. Analyses stratified by season of blood draw were not statistically different.

\section{Conclusions}

Our findings do not support an association between adulthood 25(OH)D status and postmenopausal breast cancer risk. Future studies with the ability to examine a wider distribution of $25(\mathrm{OH}) \mathrm{D}$, vitamin $\mathrm{D}$ status earlier in life, and with greater statistical power to examine tumor subtypes and stage would add importantly to the literature.

\section{Competing interests}

The authors declare that they have no competing interests.

\section{Authors' contributions}

MLM conceived of the study, participated in the design, and drafted the manuscript. VLS participated in the design, coordinated laboratory sample processing, and contributed to drafting the manuscript. RP participated in study design and conducted statistical analyses. EBB participated in study design and processed laboratory samples. EJJ participated in 
Table 2

Odds ratio (OR) and 95\% confidence interval $(\mathrm{Cl})$ between $25(\mathrm{OH}) \mathrm{D}$ levels and breast cancer risk, CPS II Nutrition Cohort women

\begin{tabular}{|c|c|c|c|c|c|c|}
\hline & \multicolumn{5}{|c|}{ Quintiles of serum 25(OH)D concentration (nmol/L) } & \multirow[t]{2}{*}{$P$ for trend ${ }^{\ddagger}$} \\
\hline & $<36.7$ & $36.7-<49.8$ & $49.8-<60.8$ & $60.8-<73.2$ & $73.2+$ & \\
\hline All cases $(n)$ & 89 & 115 & 99 & 118 & 95 & \\
\hline Controls (n) & 104 & 102 & 105 & 102 & 103 & \\
\hline OR $(95 \% \mathrm{Cl})^{*}$ & $1.00(-)$ & $1.31(0.88-1.94)$ & $1.11(0.74-1.66)$ & $1.35(0.91-2.01)$ & $1.07(0.71-1.61)$ & 0.8 \\
\hline \multirow[t]{3}{*}{ OR $(95 \% \mathrm{Cl})^{\dagger}$} & $1.00(-)$ & $1.29(0.86-1.94)$ & $1.14(0.75-1.72)$ & $1.44(0.96-2.18)$ & $1.09(0.70-1.68)$ & 0.6 \\
\hline & \multicolumn{3}{|c|}{ Tertiles of serum 25(OH)D concentration ( $\mathrm{nmol} / \mathrm{L}$ ) } & $P$ for trend $d^{\ddagger}$ & & \\
\hline & $<45.9$ & $45.9-<64.2$ & $64.2+$ & & & \\
\hline ER+ cases $(n)$ & 102 & 120 & 120 & & & \\
\hline Controls (n) & 177 & 160 & 179 & & & \\
\hline OR $(95 \% \mathrm{Cl})^{\star}$ & $1.00(-)$ & $1.32(0.94-1.87)$ & $1.16(0.82-1.63)$ & 0.4 & & \\
\hline OR $(95 \% \mathrm{Cl})^{\dagger}$ & $1.00(-)$ & $1.32(0.93-1.88)$ & $1.15(0.80-1.65)$ & 0.5 & & \\
\hline ER- cases $(n)$ & 17 & 16 & 16 & & & \\
\hline Controls (n) & 177 & 160 & 179 & & & \\
\hline OR $(95 \% \mathrm{Cl})^{\star}$ & $1.00(-)$ & $1.02(0.49-2.12)$ & $0.90(0.44-1.87)$ & 0.8 & & \\
\hline OR $(95 \% \mathrm{Cl})^{\dagger}$ & $1.00(-)$ & $1.03(0.48-2.19)$ & $0.95(0.43-2.06)$ & 0.9 & & \\
\hline In situ cases $(\mathrm{n})^{\S}$ & 34 & 39 & 30 & & & \\
\hline Controls (n) & 177 & 160 & 179 & & & \\
\hline OR $(95 \% \mathrm{Cl})^{\star}$ & $1.00(-)$ & $1.29(0.77-2.16)$ & $0.89(0.52-1.54)$ & 0.7 & & \\
\hline OR $(95 \% \mathrm{Cl})^{\dagger}$ & $1.00(-)$ & $1.23(0.72-2.09)$ & $0.87(0.49-1.55)$ & 0.7 & & \\
\hline Localized cases $(n)^{\S}$ & 90 & 114 & 114 & & & \\
\hline Controls (n) & 177 & 160 & 179 & & & \\
\hline OR $(95 \% \mathrm{Cl})^{*}$ & $1.00(-)$ & $1.44(1.01-2.06)$ & $1.25(0.88-1.79)$ & 0.2 & & \\
\hline OR $(95 \% \mathrm{Cl})^{+}$ & $1.00(-)$ & $1.45(1.01-2.09)$ & $1.30(0.90-1.89)$ & 0.2 & & \\
\hline Regional/Distant Cases (n)§ & 35 & 25 & 28 & & & \\
\hline Controls (n) & 177 & 160 & 179 & & & \\
\hline OR $(95 \% \mathrm{Cl})^{\star}$ & $1.00(-)$ & $0.79(0.45-1.38)$ & $0.79(0.46-1.37)$ & 0.4 & & \\
\hline OR $(95 \% \mathrm{Cl})^{\dagger}$ & $1.00(-)$ & $0.78(0.43-1.41)$ & $0.75(0.41-1.37)$ & 0.3 & & \\
\hline
\end{tabular}

* Unconditional logistic regression adjusted for birth year, year of blood draw, race, and season.

+ Unconditional logistic regression adjusted for birth year, year of blood draw, race, season, parity and age at first birth, body mass index at blood collection and weight change from age 18 years to blood collection.

$¥ P$ value for trend is calculated using the median for each category and modeled as a continuous variable.

$\S$ Definition of cases based on Surveillance Epidemiology and End Results (SEER) summary staging

$25(\mathrm{OH}) \mathrm{D}=25$-hydroxyvitamin $\mathrm{D} ; \mathrm{CPS}-\|=$ Cancer Prevention Study- $\|$; $\mathrm{Cl}=$ confidence interval; ER = estrogen receptor; OR = odds ratio. 
the design and contributed to drafting the manuscript. RLH conducted laboratory analyses and contributed to sections of manuscript draft. SMG participated in the design and contributed to drafting the manuscript. MJT contributed to drafting the manuscript. EEC participated in the design of the study. All authors read and approved the final manuscript.

\section{Acknowledgements}

The authors wish to thank Cari Lichtman, Daniela Dudas, Peter Briggs and the study management group for cohort and biospecimen data management.

We wish to acknowledge the untimely and tragic loss this year of our beloved colleague and friend, Eugenia "Jeanne" Calle, distinguished researcher and Vice President of Epidemiology, American Cancer Society. We miss her keen intellect, inspiring leadership, and her sense of humor.

\section{References}

1. American Cancer Society: Cancer Facts \& Figures 2009. Atlanta: American Cancer Society; 2009.

2. World Cancer Research Fund/American Institute for Cancer Research: Food, Nutrition, and the Prevention of Cancer: a Global Perspective. Washington DC AICR 2007.

3. Garland FC, Garland CF, Gorham ED, Young JF: Geographic variation in breast cancer mortality in the United States: a hypothesis involving exposure to solar radiation. Prev Med 1990, 19:614-622.

4. Norman AW: From vitamin $D$ to hormone $D$ : fundamentals of the vitamin $\mathrm{D}$ endocrine system essential for good health. Am J Clin Nutr 2008, 88:491S-499S.

5. Knight JA, Lesosky M, Barnett H, Raboud JM, Vieth R: Vitamin D and reduced risk of breast cancer: a population-based casecontrol study. Cancer Epidemiol Biomarkers Prev 2007, 16:422-429.

6. John EM, Schwartz GG, Koo J, Wang W, Ingles SA: Sun exposure, vitamin $D$ receptor gene polymorphisms, and breast cancer risk in a multi-ethnic population. Am J Epidemiol 2007, 166:1409-1419.

7. Rohan T: Epidemiological studies of vitamin $D$ and breast cancer. Nutr Rev 2007, 65:S80-83.

8. Lowe LC, Guy M, Mansi JL, Peckitt C, Bliss J, Wilson RG, Colston $\mathrm{KW}$ : Plasma 25-hydroxy vitamin D concentrations, vitamin D receptor genotype and breast cancer risk in a UK Caucasian population. Eur J Cancer 2005, 41:1164-1169.

9. Abbas S, Chang-Claude J, Linseisen J: Plasma 25-hydroxyvitamin $D$ and premenopausal breast cancer risk in a German case-control study. Int J Cancer 2009, 124:250-255.

10. Abbas S, Linseisen J, Slanger T, Kropp S, Mutschelknauss EJ, Flesch-Janys D, Chang-Claude J: Serum 25-hydroxyvitamin D and risk of post-menopausal breast cancer--results of a large case-control study. Carcinogenesis 2008, 29:93-99.

11. Bertone-Johnson ER, Chen WY, Holick MF, Hollis BW, Colditz GA, Willett WC, Hankinson SE: Plasma 25-hydroxyvitamin D and 1,25-dihydroxyvitamin $D$ and risk of breast cancer. Cancer Epidemiol Biomarkers Prev 2005, 14:1991-1997.

12. Freedman DM, Looker AC, Chang SC, Graubard BI: Prospective study of serum vitamin $D$ and cancer mortality in the United States. J Natl Cancer Inst 2007, 99:1594-1602.

13. Freedman DM, Chang SC, Falk RT, Purdue MP, Huang WY, McCarty CA, Hollis BW, Graubard BI, Berg CD, Ziegler RG: Serum levels of vitamin $D$ metabolites and breast cancer risk in the prostate, lung, colorectal, and ovarian cancer screening trial. Cancer Epidemiol Biomarkers Prev 2008, 17:889-894.

14. Calle EE, Rodriguez C, Jacobs EJ, Almon ML, Chao A, McCullough ML, Feigelson HS, Thun MJ: The American Cancer Society Cancer Prevention Study II Nutrition Cohort -- Rationale, Study Design, and Baseline Characteristics. Cancer 2002, 94:2490-2501.

15. Bergmann MM, Calle EE, Mervis CA, Miracle-McMahill HL, Thun MJ, Heath CW: Validity of self-reported cancers in a prospec- tive cohort study in comparison with data from state cancer registries. Am J Epidemiol 1998, 147:556-562.

16. Calle EE, Terrell DD: Utility of the National Death Index for ascertainment of mortality among Cancer Prevention Study II participants. Am J Epidemiol 1993, 137:235-241

17. Ersfeld DL, Rao DS, Body JJ, Sackrison JL, Miller AB, Parikh $N$, Eskridge TL, Polinske A, Olson GT, MacFarlane GD: Analytical and clinical validation of the $25 \mathrm{OH}$ vitamin $\mathrm{D}$ assay for the LIAISON automated analyzer. Clin Biochem 2004, 37:867-874.

18. Holick MF: Vitamin D deficiency. N Engl J Med 2007, 357:266-281.

19. Durrleman S, Simon R: Flexible regression models with cubic splines. Stat Med 1989, 8:551-561.

20. Wang Y, Jacobs EJ, McCullough ML, Rodriguez C, Thun MJ, Calle EE, Flanders WD: Comparing Methods for Accounting for Seasonal Variability in a Biomarker When Only a Single Sample Is Available: Insights From Simulations Based on Serum 25Hydroxyvitamin D. Am J Epidemio/ 2009, 170:88-94.

21. Chlebowski RT, Johnson KC, Kooperberg C, Pettinger $M$ Wactawski-Wende J, Rohan T, Rossouw J, Lane D, O'Sullivan MJ, Yasmeen S, Hiatt RA, Shikany JM, Vitolins M, Khandekar J, Hubbell FA, Women's Health Initiative Investigators: Calcium plus vitamin D supplementation and the risk of breast cancer. $J$ Nat/ Cancer Inst 2008, 100:1581-1591.

22. Lappe JM, Travers-Gustafson D, Davies KM, Recker RR, Heaney RP: Vitamin D and calcium supplementation reduces cancer risk: results of a randomized trial. Am J Clin Nutr 2007, 85:1586-1591.

23. Garland CF, Gorham ED, Baggerly CA, Garland FC: Re: Prospective Study of Vitamin D and Cancer Mortality in the United States. J Nat/ Cancer Inst 2008, 100:826-827.

24. Wortsman J, Matsuoka LY, Chen TC, Lu Z, Holick MF: Decreased bioavailability of vitamin D in obesity. Am J Clin Nutr 2000, 72:690-693

25. Bérubé S, Diorio C, Verhoek-Oftedahl W, Brisson J: Vitamin D, calcium, and mammographic breast densities. Cancer Epidemiol Biomarkers Prev 2004, 13:1466-1472.

26. Cui $Y$, Rohan TE: Vitamin D, calcium, and breast cancer risk: a review. Cancer Epidemiol Biomarkers Prev 2006, 15:1427-1437.

27. Shin M, Holmes MD, Hankinson SE, Wu K, Colditz GA, Willett WC: Intake of dairy products, calcium, and vitamin $D$ and risk of breast cancer. J Nat/ Cancer Inst 2002, 94:1301-1311.

28. Lin J, Manson JE, Lee IM, Cook NR, Buring JE, Zhang SM: Intakes of calcium and vitamin $\mathrm{D}$ and breast cancer risk in women. Arch Intern Med 2007, 167:1050-1059.

29. Bérubé S, Diorio C, Mâsse B, Hébert-Croteau N, Byrne C, Côté G Pollak M, Yaffe M, Brisson J: Vitamin D and calcium intakes from food or supplements and mammographic breast density. Cancer Epidemiol Biomarkers Prev 2005, 14:1653-1659.

30. John EM, Schwartz GG, Dreon DM, Koo J: Vitamin D and breast cancer risk: the NHANES I Epidemiologic Follow-up Study, 1971-1975 to 1992. Cancer Epidemiol Biomarkers Prev 1999, 8:399-406. 